\title{
Insensitivity to Unethical Behavior in Dictator Game When Indirectly Intermediated-Implications of Indirect Blindness for Safety Management
}

\author{
Atsuo Murata \\ Department of Intelligent Mechanical Systems, Graduate School of Natural Science and Technology, Okayama \\ University, Okayama, Japan \\ Email: murata@iims.sys.okayama-u.ac.jp
}

Received 8 April 2016; accepted 9 May 2016; published 12 May 2016

Copyright (C) 2016 by author and Scientific Research Publishing Inc.

This work is licensed under the Creative Commons Attribution-NonCommercial International License (CC BY-NC). http://creativecommons.org/licenses/by-nc/4.0/ (c) (i) (8) Open Access

\begin{abstract}
The aim of this study was to demonstrate that indirect mediation in behaviors leads to insensitivity to unethical behavior through a dictator game and to give some implications for safety management. The indirect involvement in the unethical behavior such as the violation of regulation is believed to lessen the responsibility and the criticism from others for the unethical behavior as compared to the direct involvement in it. The instruction condition for the evaluator of behavior in a dictator game was taken up as an experimental variable. Instruction condition 1 was to pay attention to the behavior of only a dictator. In instruction condition 2 , the participant (evaluator) was required to review all players' behavior and evaluate a dictator. It has been investigated whether allowing indirect actions (mediations) leads to reduced punishment as a function of the instruction condition. While the punishment to the indirectness did not get smaller for instruction condition 2 , the punishment to the indirectness tended to get smaller only for instruction condition 1.
\end{abstract}

\section{Keywords}

Unethical Behavior, Punishment and Fairness, Intermediation, Dictator Game, Decision Making, Safety Management

\section{Introduction}

Many studies have been carried out on punishment and fairness from the perspectives of both experimental 
economics and applied cognitive psychology. Axelrod [1] showed that punishment can lead to greater social welfare. Fehr and Schmidt [2] and Bolton and Ockenfels [3] provided a model of outcome-based fairness for explaining the relationship between punishment and fairness. Rabin [4] and Dufwenberg and Kirchsteiger [5] defined fairness in terms of both how good our action is relative to our alternatives and our belief on how nice we are. Falk and Fischbacher [6] and Falk, Fehr, and Fischbacher [7] proposed a model that combined intentions and fairness. Charness and Rabin [8] provided experimental evidence that fairness judgment and reciprocity decision are dependent on the welfare of the poorest player. Bolton, Brandts, and Ockenfels [9] provided experimental evidence that our perception of fairness depends on prior equity.

Frederick and Kahneman [10] showed that punishment and moral judgment are not merely responses to the objective wrongness of an action. Greene and Haidt [11] suggested that moral preferences are at least partially derived from an intuitive or emotional reaction. We tend to be unable to explain why we made the moral judgment that we did. Greene [12] showed that this might be explained by a dual process model of the brain. In such a way, the relationship between punishment and fairness is a very complicated social issue, and is approached from a variety of perspectives.

Companies often worry about negative reactions to price-gouging as pointed out by Kahneman, Knetsch, and Thaler [13]. Some companies try to mitigate the negative reaction of customers due to the raised price charge by intermediation using a subsidiary company. Many studies have investigated whether intermediation reduces punishment or not [2] [4]-[9] [14]-[18].

Coffman [14] examined how punishment changed when the transgressor indirectly interacted with the injured party, and explored how the third party punishment for keeping money at the expense of a poorer player changed when an intermediacy actor was included in the transaction. He showed that intermediation reduced punishment predominantly because the selfish player did not directly interact with the poorer player, and concluded that allowing indirect actions might lead to increased anti-social behaviors. In Coffman [14], only the role of each player in the dictation game was explained to each participant (evaluator). No special instructions were given to the participant. It is possible that how the punishment of a dictator is conducted depends on the viewpoint, the way of thinking, or the criterion of an evaluator. It is impossible to know what kind of strategy an evaluator used to punish a dictator from Coffman [14]. Therefore, the instruction condition was used as an experimental factor in order to confirm that the punishment of a dictator differed according to the viewpoint, the way of thinking, or the criterion of an evaluator.

Murata, Nakamura, and Karwowski [19] investigated a few cases of critical disasters or crashes that are regarded to stem from cognitive biases such as outcome bias, hindsight bias, optimistic bias, status quo bias, and loss aversion. They discussed how important it is to take cognitive biases into account for preventing incidents, crashes, collisions, or disasters. They also suggested that the lack of understanding of human's irrational and biased thinking resulted in a vicious circle [20] of similar critical crashes, collisions or disasters. They proposed that the human's fallibility to irrational and distorted thinking should be incorporated into the traditional design process of man-machine systems and safety management to prevent similar crashes, or disasters from occurring repeatedly.

It has been also indicated that gradual escalation of unsafe behavior [21], loss aversion [22], and endowment effect [23] can be root causes of critical disasters. It is expected that insensitivity to unethical behavior when indirectly intermediated, which is investigated in this study, can potentially be an undesirable risk factor in safety management. As pointed out by Surowiecki [24], outsourcing requires much time and effort of the original contractor to monitor and manage the progress of tasks conducted by a subcontractor. Indirect blindness [25] caused by outsourcing might hinder an appropriate procedure for safety management and lead to an undesirable disaster.

This study aimed at investigating how indirect mediation in a dictator game affected the punishment by an evaluator as a function of the instruction condition to an evaluator. It was hypothesized that a dictator is more severely punished by an evaluator when a dictator is indirectly concerned with the dictator game than when a dictator is directly involved in the game if an evaluator was instructed to observe the behaviors of both dictator and intermediator and evaluate a dictator. It was also hypothesized that such a phenomenon is not observed if an evaluator was instructed to observe the behavior of only a dictator. In short, we explored whether allowing indirect mediation in a dictator game leads to decreased punishment as a function of the instruction given to an evaluator (Instruction 1: The participant was required to pay attention to the behavior of only a dictator, Instruction 2: The participant was required to observe the behaviors of both dictator and intermediator and evaluate a dictator). 
As an example of relevance of this phenomenon (dilution of responsibility caused by indirectness (indirect blindness)) to industry, it has been demonstrated how this phenomenon is related to the case of the Mihama nuclear power plant disaster at Kansai Electric Power Company (KEPCO), Japan. Based on the explanation of the cause of the disaster by means of indirectness (outsourcing of making a list of piping necessary for inspection and maintenance), some implications were given for safety management.

\section{Method}

The study was conducted on March, 2015. The investigation was approved by the Ethics Committee, Dept. of Intelligent Mechanical Systems, Okayama University.

\subsection{Participants}

Twenty undergraduate or graduate students (ten male and ten female) aged from 20 to 23 years old took part in the experiment. All belonged to Dept. of Intelligent Mechanical Systems, Okayama University, and had no knowledge or skill in psychology or behavioral economics. All agreed with the participation in the experiment after receiving a brief explanation of the contents and the procedure of the experiment.

\subsection{Task, Design, and Procedure}

A four-person dictator game (DG) was used to verify the hypothesis above. Four players A, B, C, and D were involved in this game. Player A was provided with $\$ 10$ for participation. Players B and D were provided with $\$ 5$ for the participation. Player $\mathrm{C}$ cannot receive a reward for participation, and was paid according to DG. Players A and B were also paid according to DG. Player D was not paid according to DG.

Player A owned the right to split $\$ 10$ with Player $C$, and decided how to split $\$ 10$. Player $C$ had no right to reject the offer by Player A, and must simply obey Player A's decision (Case 1 in Figure 1). Player A could sell the right to play a dictator game to Player B by paying Player B less than $\$ 10$. Player B had no right to reject Player A's decision (Case 2 in Figure 2). Player D (evaluator) had a right to reduce Player A's payoff by monitoring the situation of a dictator game according to the instruction condition to be given later. Player $\mathrm{D}$ could punish Player A by reducing his or her earned money until his or her money was zero.

The within-subject experimental factor was the directness of the dictator game (two levels: directly play DG (direct (unsold) condition) or sell the right to play DG to Player B (indirect (unsold) condition). The betweensubject experimental factor was the instruction for evaluating the behavior of Player A (dictator). Instruction condition 1 was to pay much attention to the behavior of a dictator. In instruction condition 2, the participant was

\section{Case 1}

Players A, B, and D will be given show up fee. Player A was also paid according to DG. Player $C$ is given only the money allocated by Player A or B during the experimental game.

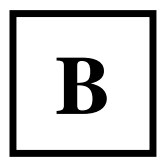

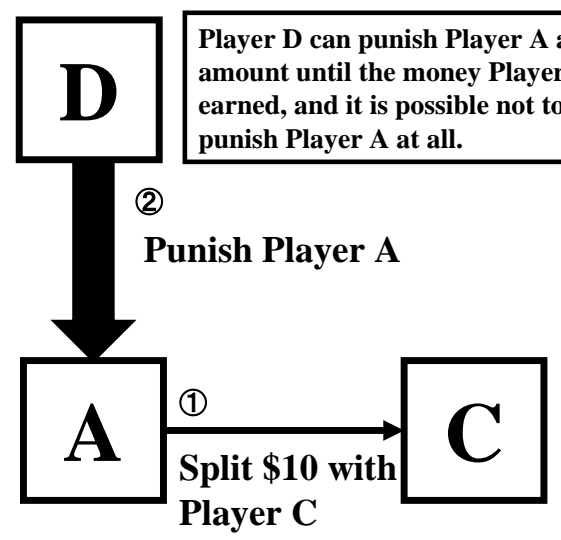

Player A own the right to split \$10 with Player C. Player $C$ has no say in the decision by Player A.

Figure 1. Explanation of the procedure of experiment (Case 1: Player A directly plays a dictator game with Player C). 


\section{Case 2}

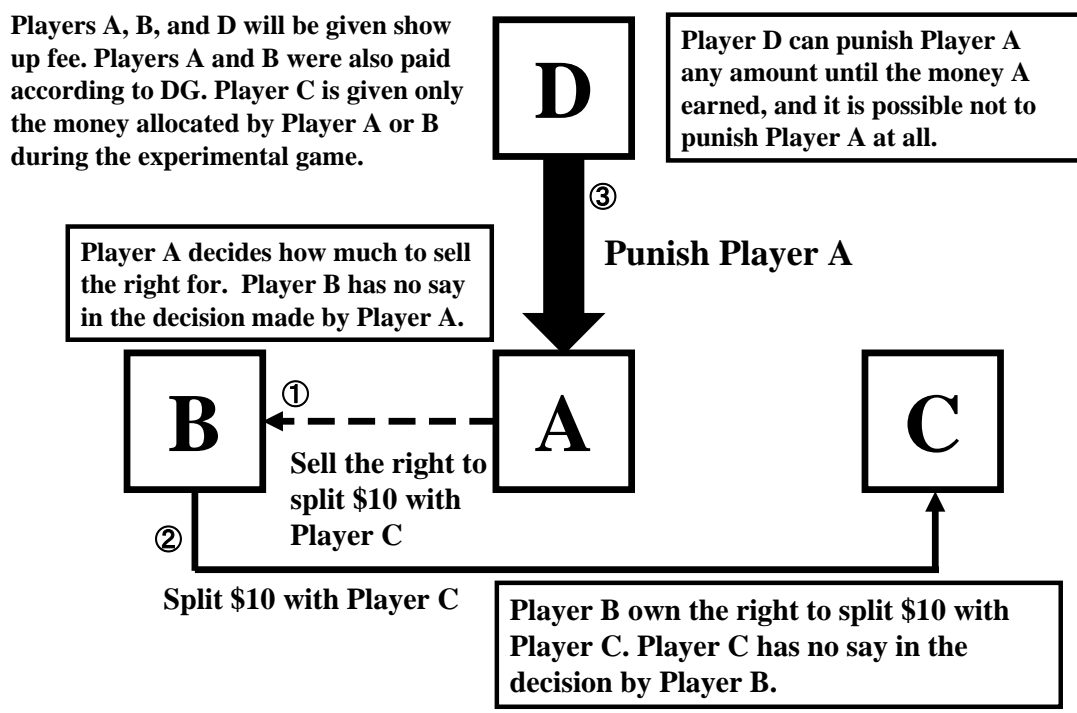

Figure 2. Explanation of the procedure of experiment (Case 2: Intermediation condition, Player A sells the right to play a dictator game to Player B by receiving money less than \$10 from Player B. Player B directly plays a dictator game with Player C).

required to review all players' behaviors and evaluate the dictator. Ten participants were randomly allocated to one of instruction conditions. The order of performance of the two conditions of directness (direct and indirect conditions) of the dictator game was counterbalanced across the participants.

The experimental task was simulated and programmed on a PC. It must be noted that the participants only played the role of Player D (evaluator). The computer agent acted the roles of Players A, B, and C. This is apparently different from the experiment in Coffman [14]. As the number of participants in Coffman [14] was 24, the number of participants is justified to be appropriate. The aim of this study was to investigate the effect of the instruction condition on the behavior of Player $\mathrm{D}$ (evaluator) and explore whether the intermediation reduces the punishment by an evaluator as a function of the instruction condition. Therefore, the roles of Players A, B, and C were played by computer agents. In order to keep the reality of the experiment, Player D (participant) was informed that Players A, B, and C were playing the game at separate rooms.

\section{Results}

The data were statistically analyzed using analysis of variance (ANOVA). A two-way (involvement in the dictator game (direct or indirect) by instruction condition) ANOVA was conducted on the amount of punishment. A significant main effect of instruction condition $(\boldsymbol{F}(1,18)=4.549, p<0.05)$ was detected. An involvement by instruction condition interaction was also significant $(\boldsymbol{F}(1,18)=4.892, p<0.05)$. The interaction of punishment between the instruction condition and the involvement in the dictator game is plotted in Figure 3.

In instruction condition 1, the participants (Player D) were required to punish Player A according to the predetermined rule and by paying attention to the behavior of a dictator (Player A). Under instruction condition 1, Player D's amount of punishment to Player A in the direct condition (unsold) was larger than that in the indirect condition (sold) (see Figure 4(a)). This indicates that indirect intermediation by selling the right to play DG to Player B leads to less punishment. This agreed with the result of Coffman [14] that the punishment to the indirect condition gets smaller.

In instruction condition 2, the participants were required to properly monitor the behavior of all players (in particular, Players A and B) and decide how much the behavior of Player A is punished. Player D's amount of punishment to Player A in the indirect condition was larger than that in the direct condition (see Figure 4(b)). The result conflicts with the result of instruction condition 1 and the finding by Coffman [14] that the indirect intermediation reduces the punishment and thus lessons the responsibility for the unethical violation behavior. 


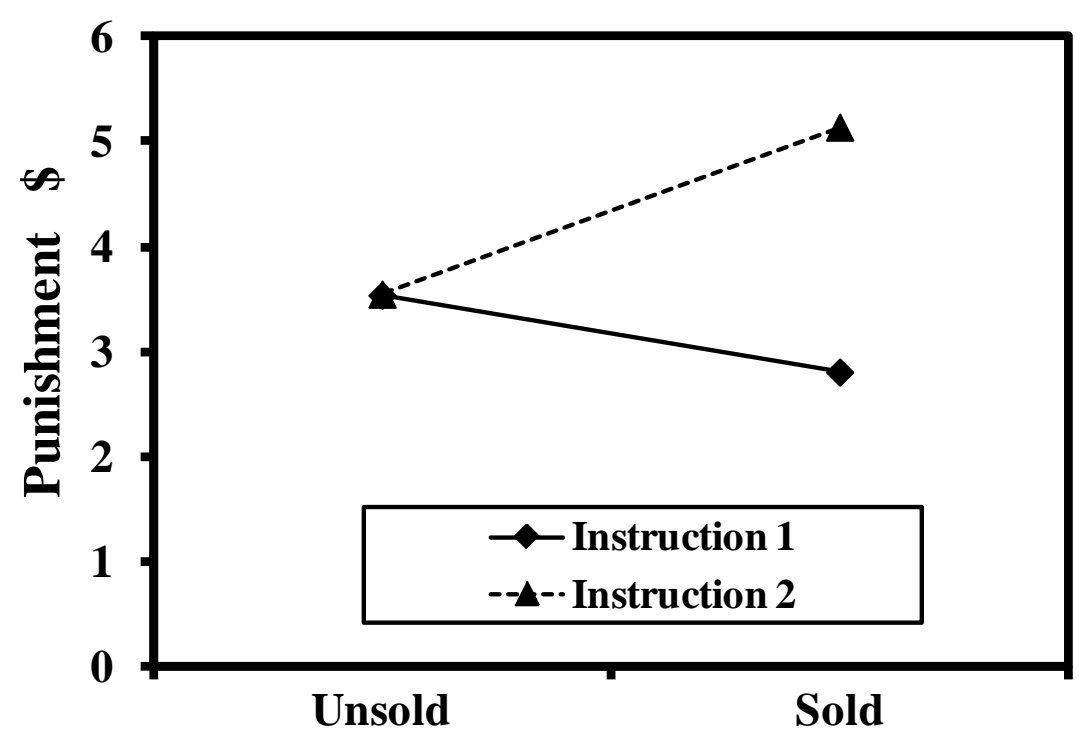

Figure 3. Mean punishment as a function of whether the right to play DG with Player C was sold to Player B or not and instruction condition. Instruction condition 1: pay attention to the behavior of only Player A (dictatror), Instruction condition 2: pay attention to the behavior of all players.

\section{(a) Instruction condition 1}

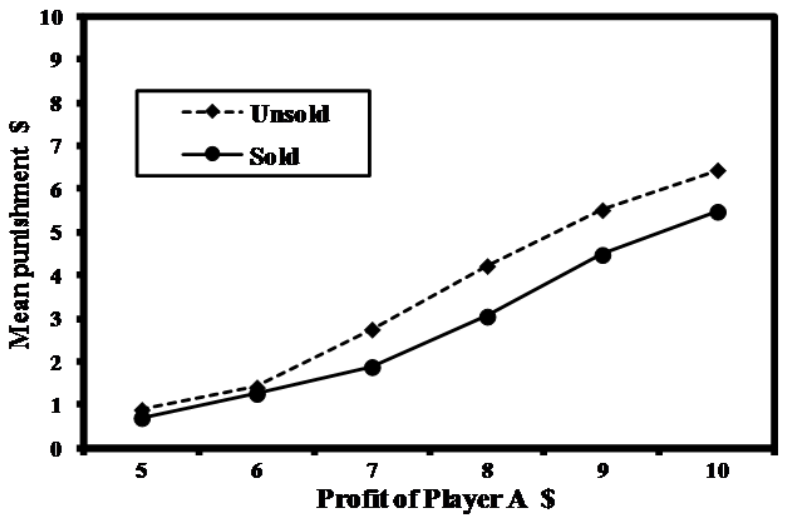

(b) Instruction condition2

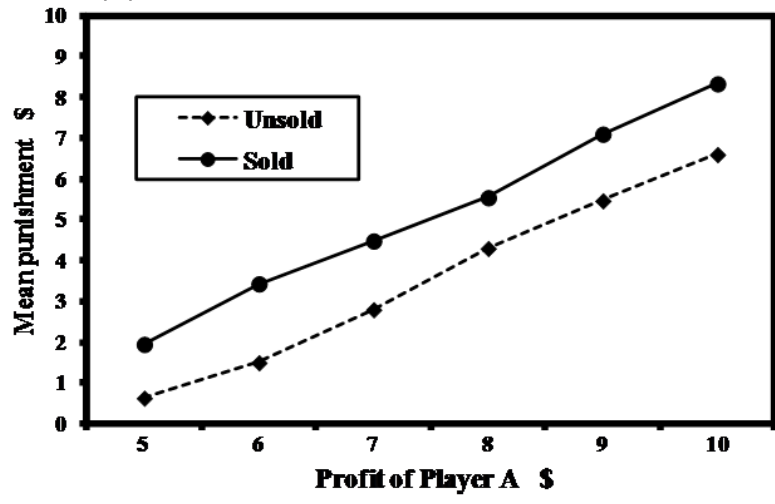

Figure 4. Mean punishment as a function of profit of Player A and whether the right to play DG with Player C was sold to Player B or not. (a) instruction condition 1: pay attention to the behavior of only Player A (dictatror), (b) instruction condition 2: pay attention to the behavior of all players.

\section{Discussion}

\subsection{Effect of Instruction Condition on Punishment to Unethicality}

Coffman [14] examined how punishment changed when the transgressor (Player A) indirectly interacted with the injured party (Player C) by exploring how third party (Player D) punishment for keeping money at the expense of a poorer player (Player C) changed when an intermediacy actor (Player B) was included in the transaction. He hypothesized that intermediation reduced punishment predominantly because the selfish player did not directly interact with the poorer player when intermediation was used. He concluded that intermediation by allowing indirect actions might lead to increased anti-social behaviors.

In Coffman [14], only the role of each player was explained to the participant. No special instructions or emphases were given to the participant. In this study, instruction condition 1 was to pay much attention to the behavior of a dictator (Player A). In instruction condition 2, the participant was required to review the behaviors of both Players A and B and evaluate a dictator. If the behavior of Player D (punishment of Player A) is based on 
only the behavior of Player A like instruction condition 1, and this was emphasized to Player D, it might be possible that intermediation by an actor (Player B) gets smaller punishment. However, if the evaluator (Player D) is instructed to carefully observe the behaviors of Players A and B and evaluate fairly the behavior of both Players A and B (like instruction condition 2), this might not lead to the smaller punishment of the indirect condition. This might rather punish the indirect condition intermediated by Player B more severely than the direct condition.

It is possible that how the punishment of Player A is conducted depends on the viewpoint, the way of thinking, or the criterion of Player D. It is impossible to know what kind of strategy the evaluator (Player D) used to punish Player A from Coffman [14]. Therefore, this study used the instruction condition as an experimental factor in order to confirm that the punishment of Player A differs according to the viewpoint, the way of thinking, or the criterion of Player D.

In the instruction condition 1, it was hypothesized that Player A is more severely punished by Player D when Player A is directly involved in the dictation game than when Player A is indirectly involved in the game (Hypothesis 1). We might tend to be more insensitive to violation, defection, or unethical behavior when it was indirectly intermediated by an intermediacy actor than when a dictator was directly concerned with it. As shown in Figure 4(a), Player D's amount of punishment to Player A in the direct involvement was larger than that in the indirect condition. This was in agreement with Hypothesis 1 above, and indicates that indirect intermediation by selling the right to play DG to Player B leads to less punishment of Player A by Player D. The result corresponds with the finding by Coffman [14] and Bazerman and Tenbrunsel [25] that the indirect intermediation reduces the punishment and thus lessens the responsibility for the unethical behavior. It seems that third party (Player D) punishment for keeping money at the expense of a poorer player (Player C) decreases when an intermediary actor (Player B) is included in the game.

On the other hand, in instruction condition 2, it was hypothesized that Player A is more severely punished by Player D when Player A is indirectly concerned with the dictator game than when Player A is directly involved in it (Hypothesis 2). As shown in Figure 4(b), Player D's amount of punishment to Player A in the indirect involvement was larger than that in the direct condition. Although this was in agreement with Hypothesis 2 above, this was in conflict with the finding by Coffman [14]. The finding on Hypothesis 2 is generally in agreement with the findings on behavioral economics or cognitive psychology on punishment and fairness that we tend to punish intermediation more severely and frequently [2] [6] [8] [16].

Figure 3 also confirms that the punishment to Player A for the intermediation condition differs characteristically between the two instruction conditions. The reduced punishment due to the intermediation was observed only for instruction condition 1. It might be postulated that the participants in instruction condition 2 pay more emphasis on the outcome than on the intermediation, while the participants in instruction condition 1 and Coffman [14] paid more emphasis on Player A's unfair strategy of intermediation by letting Player B intermediate (play) the dictator game instead of Player A. The result observed in instruction condition 1 and Coffman [14] corresponds to indirect blindness pointed out by Bazerman and Tenbrunsel [25]. Bazerman and Tenbrunsel [25] suggested that indirect blindness leads to an organizational unethical behavior, and lessens the impact of the unethical behavior itself. The result in instruction condition 2 suggests how one can avoid indirect blindness. Paying attention to an individual behavior like instruction condition 1 led to indirect blindness, while instruction condition 2 to review and observe all players' behaviors did not lead to indirect blindness (cf. Figure 4(a) and Figure 4(b)). In this manner, this study suggests that paying attention not to the individual behavior but to the behavior of the organization as a whole would be important and help to remove the influence of indirect blindness.

As hypothesized, only when the participant was instructed to properly monitor the behavior of Player A and decided how much punishment they (evaluator) gave Player A (dictator), the intermediation led to less punishment. In other words, Player D punished Player A more severely for the unsold condition (direct condition) than for the sold condition (intermediation (indirect) condition). The strategy on the evaluation of Player A by Player $\mathrm{D}$ might change according to the instruction condition. These results might mean that the punishment to the indirectness does not always get smaller. The punishment to the indirectness gets smaller only when the participants were instructed to place much emphasis on properly monitoring the behavior of Player A. In summary, the hypothesis that the indirect intermediation reduces the punishment and thus lessens the responsibility for the unethical behavior is true only for the limited condition (instruction condition 1). Therefore, we must be very 
careful when interpreting such intermediated unethical behavior.

\subsection{Implications for Safety Management}

Murata, Nakamura, and Karwowski [19] showed that cognitive biases such as outcome bias and hindsight bias distort decision making and lead to critical unfavorable disasters, collisions, or crashes. On the basis of the results of this experiment that the punishment of the indirect mediation was smaller than that of the direct involvement when the evaluator did not pay attention to all involved in a dictator game, it was speculated that the indirect intermediation might lessens the responsibility for the unethical behavior. Thus, it is plausible that indirectness, together with gradual erosion (e.g., Murata [21]), hindsight (e.g. Murata and Matsushita [26]) and outcome bias (e.g., Murata and Nakamura [27]), leads to an optimistic bias, dilutes responsibility, and eventually becomes a trigger of critical crash, collision, or disasters as shown in Figure 5. Such a phenomenon (dilution of responsibility or less punishment caused by indirectness) can be observed in the following case of the Mihama nuclear power plant disaster at KEPCO, Japan and the relevance of this study to industry is discussed using this case.

The Mihama Nuclear Power Station Unit 3 (pressurized water reactor (PWR) with a rated electric power output of $826 \mathrm{MW}$ and a rated thermal power output of $2440 \mathrm{MW}$ ) was operating at the rated thermal power output, when an alarm indicating a nonconformance between 3A-SG feed water and steam flow actuated at 15:28 on 9, August in 2004. The alarm meant that the feed water to one of steam generators of the unit was insufficient. This resulted in an automatic reactor trip, followed by an automatic turbine trip. Immediately after the event, the turbine building was filled with steam and eleven people were injured (five people died).

In the maintenance guideline of the secondary system piping at KEPCO, the fractured piping was categorized as "the major systems subject to inspection (whose remaining age must be under control and which must be inspected immediately according to schedule)". The fractured region of the piping, in fact, was losing its width due to the interactive effect of erosion and corrosion. Although the standard width of the piping must be $4.7 \mathrm{~mm}$, the minimum width of the piping around the fractured region was only $0.4 \mathrm{~mm}$. The deterioration of piping is

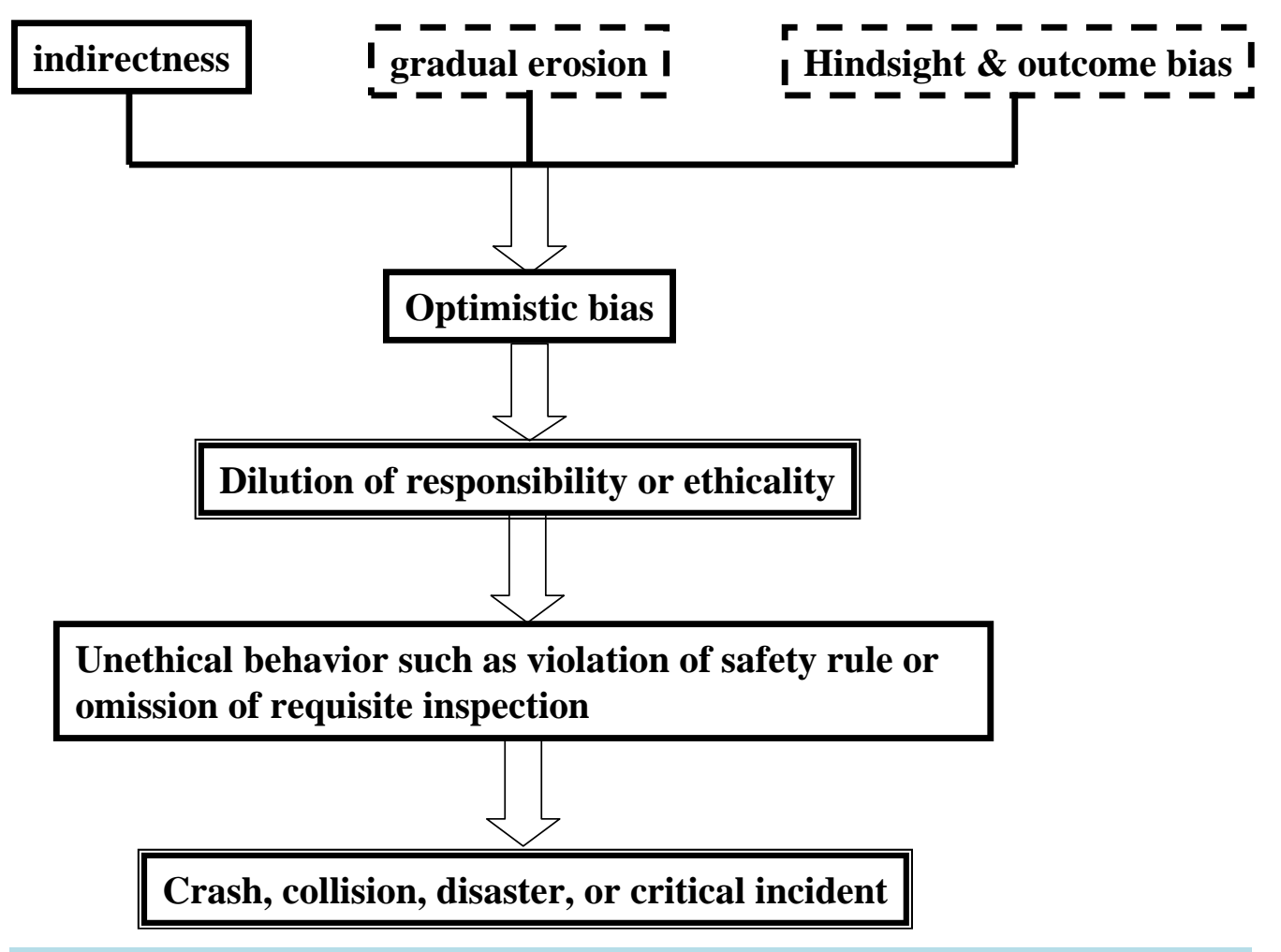

Figure 5. A model that explains how indirectness, together with gradual erosion and hindsight and outcome bias, leads to an optimistic bias and dilute responsibility, and eventually becomes a trigger of critical crash, collision, or disasters. 
scientifically predictable. However, this has not been inspected in the past because the region was not registered to the maintenance management system of piping systems. On April in 2003, KEPCO's cooperating company (subcontractor 3 in Figure 6) checked the list of the maintenance management system and found the fractured region of the piping was not registered to the maintenance list. Therefore, the relevant region was planned to be inspected and maintained in 2004. Before the inspection and maintenance of the relevant region was conducted, this disaster had occurred. The discussion is made concerning the reason why the inspection and maintenance of such a critical region of piping was delayed due to the failure to register to the list of the maintenance and management system.

\section{(Outsourcing)}
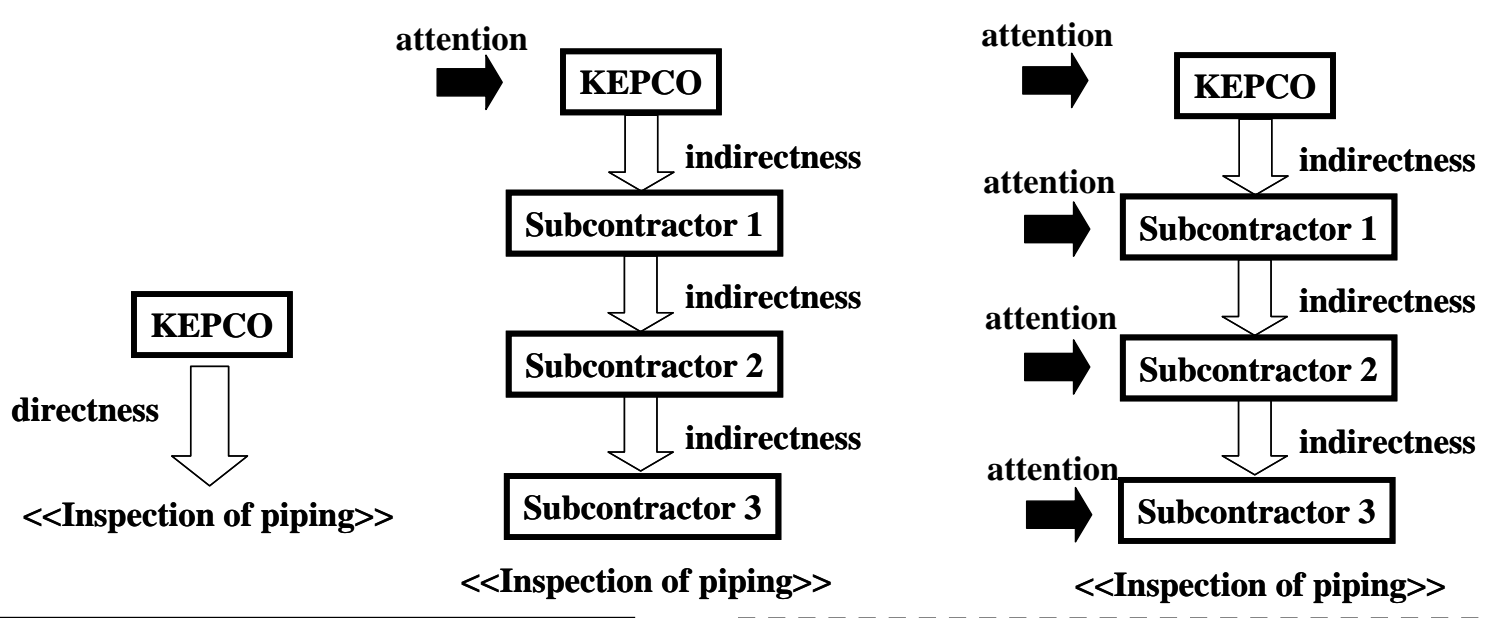

When paying attention to only KEPCO

Less punishment of KEPCO's indirectness

by chain of subcontractors.

One is less readily aware of the unethicality of KEPCO.

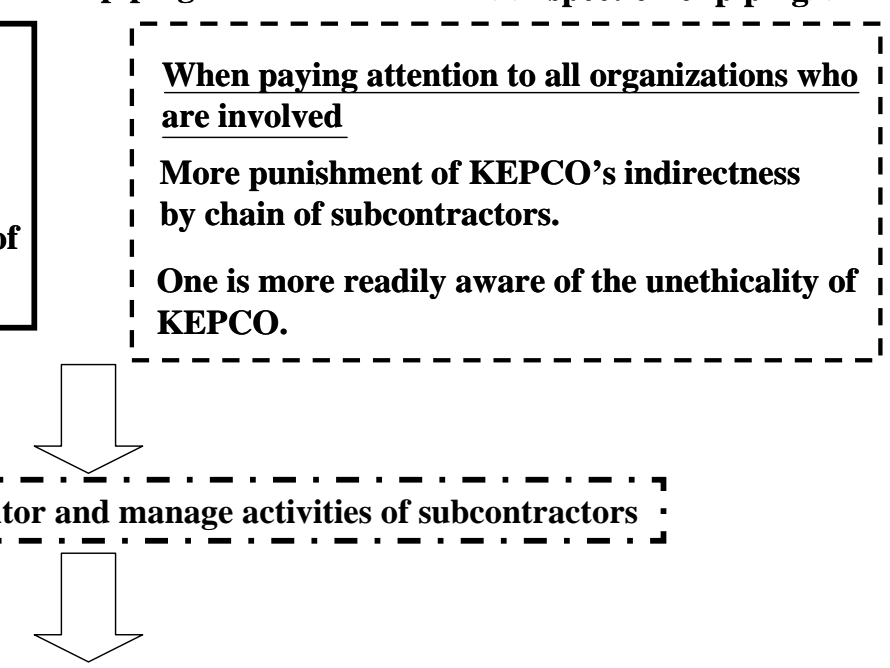

Indirectness makes the responsibility of KEPCO dilute, especially when attentions were paid only to KEPCO. KEPCO does not actively monitor and manage the maintenance activities of subcontractors and attempt to instruct subcontractors to thoroughly execute the inspection of piping.

Optimistic bias $\Rightarrow$ no active monitor and manage activities of subcontractors

L. - . - _ . - - - .

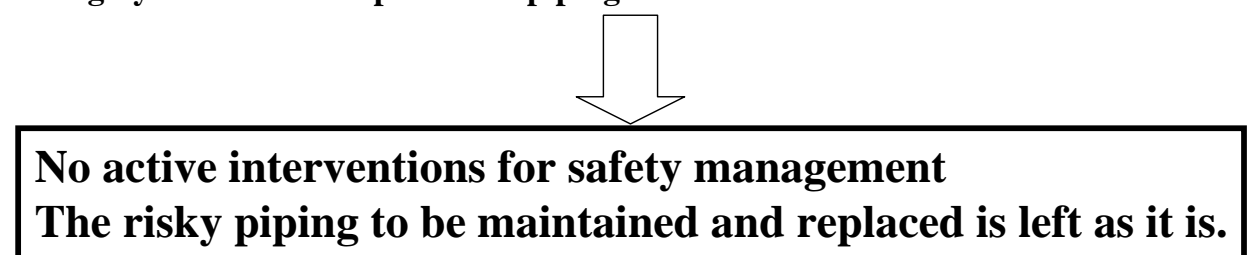

Figure 6. An explanation of KEPCO disaster when the piping inspection was indirectly intermediated by subcontractors and consequently the maintenance of fractured pipes was left as it was. 
The task of writing out a document of the list of piping necessary for inspection and maintenance was conducted via a chain of three subcontractors (see Figure 6). Furthermore, only one worker at subcontractor 3 engaged in making the list of maintenance and management system that included about 63,000 areas to be inspected and maintained. This was definitely overloaded for one worker, and inevitably caused the laps of registering the fractured area of piping to the list.

Outsourcing requires much time and effort for the original contractor to monitor and manage the progress of tasks conducted by a subcontractor, and this is called transaction cost [24]. KEPCO did not pay the transaction cost and ensure that subcontractors were doing what they promised they would conduct. Although the subcontractors did not conceal the information concerning the inspection and maintenance list of piping, they did not actively explain the laps of registration to the list to KEPCO. KEPCO only outsourced the task to make a list of maintenance management system, and did not appropriately monitor and manage the progress of tasks.

As shown in this study, it tends that outsourcing to subcontractors $1-3$ leads to the dilution of responsibility of the original contractors due to indirectness. This result indicates that directness through outsourcing caused the passive and irresponsible attitude of KEPCO towards the inspection and maintenance of piping system.

In summary, indirectness eventually led to an optimistic bias (see Figure 5), which diluted the responsibility of KEPCO. Consequently, KEPCO did not engage in the monitoring and management activities of subcontractors' inspection of piping systems. In other words, KEPCO did not attempt to require subcontractors to thoroughly execute the inspection of piping. Inevitably, no active interventions for safety management were conducted by KEPCO, and the fractured and risky piping to be maintained and replaced immediately was left as it was.

The relevance of the results to industrial applications was explained by referring to the example of a disaster occurred at the Mihama Nuclear Power Station Unit 3, KEPCO. Paying attention to indirectness that arises as a result of outsourcing to multiple subcontractors and analyzing the Mihama Nuclear Power Plant disaster, the following implications for safety management can be given. It must be bear in mind that outsourcing causes indirectness (eventually optimistic bias) and can induce a situation under which the progress of tasks conducted by subcontractors is not actively monitored and managed. The unethical behavior cause by indirectness might be to some extent suppressed when paying attention to all organizations involved.

At present, it is impossible to directly relate the results to occurrence mechanism of crashes, collisions, disasters, or critical incidents. Moreover, it has not been quantitatively shown how biases (including indirectness) in Figure 5 are related to crashes, collisions, disasters, or critical incidents. Future research should develop a quantitative model how a variety of cognitive biases interlace or interact and work as a risk factor of crashes, collisions, disasters, or critical incidents.

\section{Conclusions}

It has been investigated whether allowing indirect actions (intermediations) leads to the reduced amount of punishment as a function of the instruction condition. The punishment to indirectness did not necessarily get smaller for instruction condition 2. The punishment to indirectness tended to get smaller only when the participant was required to pay attention to the behavior of only a dictator. In this manner, it was verified that the indirect intermediation reduces the punishment and thus lessens the responsibility for the unethical violation behavior under the limited condition (instruction condition 1).

Future research should explore the effects of reward of Players A, B, and D on the amount of punishment by the evaluator (Player D) more systematically in order to identify the condition of intermediary reduction of punishment.

The following implications for safety management can be given:

- It should be noted that outsourcing causes indirectness, makes us insensitivity to unethical, undesirable, or irresponsible behavior, and has a potential risk that the progress of tasks conducted by a subcontractor is not actively monitored and managed by the original contractor.

- The unethical behavior (no active monitor and management of subcontractors duty) caused by indirectness is to some extent suppressed when paying attention to all organizations involved.

\section{Acknowledgements}

This work was partly supported by Grant-in Aid for Scientific Research (B) (22310101 \& 26282095), Japan Society for the Promotion of Science (JSPS). 


\section{References}

[1] Axelrod, R. (1986) An Evolutionary Approach to Norms. American Political Science Review, 80, 1095-1111. http://dx.doi.org/10.2307/1960858

[2] Fehr, E. and Schmidt, K.M. (1999) A Theory of Fairness, Competition, and Cooperation. Quarterly Journal of Economics, 114, 817-868. http://dx.doi.org/10.1162/003355399556151

[3] Blton, G. and Ockenfels, A. (2000) ERC: A Theory of Equity, Reciprocity and Competition. American Economics Review, 90, 166-193. http://dx.doi.org/10.1257/aer.90.1.166

[4] Rabin, M. (1993) Incorporating Fairness into Game Theory and Economics. American Economic Review, 83, 12811302.

[5] Dufwenberg, M. and Kirchsteiger, G. (2004) A Theory of Sequential Reciprocity. Game and Economic Behavior, 47, 268-298. http://dx.doi.org/10.1016/j.geb.2003.06.003

[6] Fehr, E. and Fischbacher, U. (2004) Third Party Punishment and Social Norms. Evolution and Human Behavior, 25, 63-87. http://dx.doi.org/10.1016/S1090-5138(04)00005-4

[7] Falk, F., Fehr, E. and Fischbacher, U. (2005) Driving Force behind Informal Sanctions. Econometrica, 73, $2017-2030$. http://dx.doi.org/10.1111/j.1468-0262.2005.00644.x

[8] Charness, G. and Rabin, M. (2002) Understanding Social Preferences with Simple Tests. Quarterly Journal of Economics, 117, 817-869. http://dx.doi.org/10.1162/003355302760193904

[9] Bolton, G., Brandts, J. and Ockenfels, A. (2005) Fair Procedures: Evidence from Games Involving Lotteries. The Economic Journal, 115, 1054-1076. http://dx.doi.org/10.1111/j.1468-0297.2005.01032.x

[10] Frederick, S. and Kahneman, D. (2002) Representativeness Revisited: Attribute Substitution in Intuitive Judgment. In: Gilovich, T., Griffin, D. and Kahneman, D., Eds., Heuristics and Biases: The Psychology of Intuitive Judgment, Cambridge University Press, Cambridge, 49-81.

[11] Greene, J. and Haidt, J. (2002) How (and Where) Does Moral Judgment Work? Trends in Cognitive Sciences, 6, 517523. http://dx.doi.org/10.1016/S1364-6613(02)02011-9

[12] Greene, J. (2007) Why Are VMPFC Patients More Utilitarian? A Dual-Process Theory of Moral Judgment Explains. Trends in Cognitive Sciences, 11, 322-323. http://dx.doi.org/10.1016/j.tics.2007.06.004

[13] Kahneman, D., Knetsch, J. and Thaler, R. (1986) Fairness as a Constraint on Profit-Seeking. The American Economic Review, 76, 728-741.

[14] Coffman, L.C. (2011) Intermediate Reduces Punishment (and Reward). American Economic Journal: Microeconomics, 3, 77-106. http://dx.doi.org/10.1257/mic.3.4.77

[15] Charness, G. (2004) Attribution and Reciprocity in a Simulated Labor Market: An Experimental Investigation. Journal of Labor Economics, 22, 665-688. http://dx.doi.org/10.1086/383111

[16] Carpenter, J. and Matthews, P.H. (2009) What Norms Trigger Punishment? Experimental Economics, 12, $272-288$. http://dx.doi.org/10.1007/s10683-009-9214-z

[17] Falk, A. and Fischbacher, U. (2006) A Theory of Reciprocity. Games and Economic Behavior, 54, $293-315$. http://dx.doi.org/10.1016/j.geb.2005.03.001

[18] Engleman, D. and Strobel, M. (2004) Inequality Aversion, Efficiency, and Maximum Preferences in Simple Distribution Experiments. American Economic Review, 94, 857-869. http://dx.doi.org/10.1257/0002828042002741

[19] Murata, A., Nakamura, T. and Karwowski, W. (2015) Influence of Cognitive Biases in Distorting Decision Making and Leading to Critical Unfavorable Incidents. Safety, 1, 44-58. http://dx.doi.org/10.3390/safety1010044

[20] Dekker, S. (2006) The Field Guide to Understanding Human Error. Ashgate Publishing, Burlington.

[21] Murata, A. (2015) On Verification of Gradual Escalation Phenomenon of Violation Behavior Using an Experimental Paradigm of Diversification of Risk. Psychology Research, 5, 197-204.

[22] Murata, A. (2015) Loss Aversion Underlying Violation. Psychology Research, 5, 225-231.

[23] Murata, A. (2015) On Persistency of Endowment Effect-Relationship between Affection and Endowment Effect. Psychology Research, 5, 287-291.

[24] Surowiecki, J. (2004) The Wisdom of Crowds. Anchor Books, New York.

[25] Bazerman, M.H. and Tenbrunsel, A.E. (2011) Blind Spot. Princeton University Press, Princeton.

[26] Murata, A. and Matsushita, Y. (2014) Hindsight Bias in Cause Analysis of Accident. Psychology Research, 4, 843-851.

[27] Murata, A. and Nakamura, T. (2015) Effect of Intention on Outcome Bias in Decision Making-Implications for Safety Management. Journal of Behavioral and Brain Science, 5, 561-569. http://dx.doi.org/10.4236/jbbs.2015.513053 